\title{
EPISTEMOLOGIA, HISTÓRIA E ENSINO DA MATEMÁTICA: REFLEXÕES SOBRE FORMAÇÃO E APRENDIZAGEM SIGNIFICATIVA
}

\section{EPISTEMOLOGY, HISTORY AND TEACHING OF MATHEMATICS: REFLECTIONS ABOUT FORMATION AND SIGNIFICANT LEARNING}

\begin{abstract}
Marcos Alexandre Alves
Centro Universitário Franciscano/Programa de Pós-graduação em Ensino de Ciências e Matemática, e-mail: maralexalves@gmail.com

Karla Jaqueline Souza Tatsch

Centro Universitário Franciscano/Programa de Pós-graduação em Ensino de Ciências e Matemática, e-mail: karlasouzat@hotmail.com
\end{abstract}

\section{Resumo}

Este artigo apresenta uma reflexão acerca da teoria histórico-epistemológica de Lakatos, com ênfase no conhecimento matemático, cujo propósito é provocar reflexões acerca da formação e da prática docente, por meio de uma relação com a teoria da aprendizagem significativa, proposta por Moreira. Propõe-se, expor as diretrizes metodológicas dos Programas de Pesquisa Científica, ressaltar a importância dos aspectos históricos e epistemológicos na produção do conhecimento matemático, questionar o predomínio, no ensino da matemática, de uma concepção empírico-indutivista, defender a promoção de uma prática educativa que estimule um ensino interdisciplinar e contextualizado, o entrelaçamento de saberes das diferentes áreas, a valorização do conhecimento específico como instrumento para estabelecer e compreender suas relações entre as diferentes áreas. Enfim, intenciona-se fomentar uma aprendizagem que seja significativa e voltada para o desenvolvimento da racionalidade crítica, em que os estudantes são incentivados a assumir uma atitude ativa e participativa nas discussões e no desenvolvimento das ideias matemáticas.

Palavras-chave: Racionalidade crítica, Filosofia da Matemática, Ensino interdisciplinar, Aprendizagem significativa, Atitude ativa.

\section{Abstract}

This article presents a reflection on the historical-epistemological theory of Lakatos, with an emphasis on mathematical knowledge, whose purpose is to provoke reflections about the formation and teaching practice, through a relation with the theory of meaningful learning, proposed by Moreira. It is proposed, to expose the methodological guidelines of the Programs of Scientific Research, to emphasize the importance of historical and epistemological aspects in the production of mathematical knowledge, to question the predominance, in the teaching of mathematics, of an empirical-inductive conception, defend the promotion of an educational practice that stimulates an interdisciplinary and 
contextualized teaching, the interweaving of knowledge of the different areas, the valuation of specific knowledge as an instrument to establish and understand their relationships between the different areas. Finally, it is intended to foster a learning that is meaningful and focused on the development of critical rationality, in which students are encouraged to take an active and participatory attitude in the discussions and development of mathematical ideas.

Keywords: Critical Rationality, Philosophy of Mathematics, Interdisciplinary Teaching, Significant Learning, Active Attitude.

\section{Introdução}

O processo de ensino e aprendizagem da Matemática está relacionado a elementos que, muitas vezes, tem levado os alunos a enfrentarem dificuldades na compreensão dessa importante área do conhecimento. Nesse contexto, torna-se necessário analisar o processo de formação do professor de Matemática. Essa formação precisa fornecer ao futuro docente a compreensão dos elementos que conduzem à apreensão do conhecimento matemático, na tentativa de oferecer meios para que a aprendizagem se efetive de forma ativa e significativa, influenciando positivamente na vida individual e social do estudante. Para isso, torna-se imperativo conceber que a Matemática é um campo de atividade humana e, como tal, está imbuída de aspectos históricos e epistemológicos que envolvem o desenvolvimento do homem e da sociedade (BYNUM, 2013).

Dentre os aspectos histórico-epistemológicos relacionados ao ensino de Matemática, busca-se discutir, nesse artigo, os fundamentos teóricos do pensamento de Imre Lakatos, epistemólogo racionalista crítico, que muito se dedicou ao estudo da Filosofia da Matemática, refletindo sobre o desenvolvimento da ciência a partir da sua Metodologia dos Programas de Investigação Científica (1989). Desenvolveu, por assim dizer, uma Filosofia da Matemática que denominou quase empirismo, levando em consideração a atividade dos matemáticos, isto é, o que eles fazem e têm feito, com todas as imperfeições inerentes a qualquer atividade ou criação humana, no desenvolvimento dessa ciência.

Para isso, apresenta-se uma reflexão sobre a epistemologia de Imre Lakatos, no que tange aos aspectos relacionados ao processo de ensino e aprendizagem na área da Matemática. O objetivo é produzir um conjunto reflexões que haverão de subsidiar os professores, tanto em formação continuada quanto inicial. A proposta consiste em desenvolver uma provocação sobre a importância do conhecimento e da exploração de aspectos históricos e epistemológicos para que se conquiste um processo de ensino que contemple a formação humana do aluno, preparando-o para sua vida em sociedade. Destaca-se, nesse contexto, a relevância do conhecimento científico como instrumento fundamental para se despertar a condição critico-reflexiva.

Cientes de que, na maioria das vezes, as reflexões e as ideias dos teóricos estão condicionadas às suas vivências históricas, sociais e científicas, considera-se relevante iniciar a presente análise conferindo destaque a alguns aspectos inerentes à biografia e 
obra de Imre Lakatos, que nasceu em Debrecen na Hungria em 1922. Judeu, de nome Imre Lipschitz, teve sua vida dominada pelos problemas resultantes do poder nazista e da Segunda Guerra Mundial. Com sua mãe e avó mortas em Auschwitz (Sul da Polônia), mudou seu nome para Imre Molnár, buscando evitar a perseguição nazista.

Nos anos seguintes, participou ativamente dos movimentos antinazistas, durante a Segunda Guerra Mundial, e quando ela terminou alterou seu sobrenome para Lakatos, cujo significado é "serralheiro". Em 1944 se formou em Matemática, Filosofia e Física na Universidade de Debrecen e quatro anos mais tarde continuou seus estudos de doutorado, onde frequentou os seminários de Georg Lukács. Estudou na Universidade Estatal de Moscou, sob a supervisão de Sofya Yanovskaya e retornou à Hungria, vindo trabalhar como oficial no Ministério da Educação.

Contudo, dadas suas dificuldades em aceitar a forma como a sociedade estava sendo conduzida, foi preso de 1950 a 1953, por problemas com as autoridades russas. Depois de sua libertação, Lakatos regressou à vida acadêmica desenvolvendo pesquisas em Matemática e vivendo de traduções, época em que traduziu a obra sobre resolução de problemas "How to solve it" do também húngaro George Polya.

Nessa etapa de vida, Lakatos envolveu-se e participou ativamente de grupos estudantis, numa altura em que viria a dar a Revolução Húngara e, em 1956, quando a Revolução foi abortada pela invasão dos russos, fugiu para Viena (Áustria) e depois para a Inglaterra, onde se doutorou em Filosofia da Ciência pela Universidade de Cambridge, em 1961, cuja tese de doutorado embasou o livro A Lógica do Descobrimento Matemático: Provas e Refutações (1978), publicado após sua morte, ocorrida em 1974.

Em 1960, Lakatos foi nomeado professor na London School of Economics, local em que desenvolveu seu trabalho sobre Filosofia da Matemática e Filosofia da Ciência e, em 1970, editou a obra A Crítica e o desenvolvimento do Conhecimento (1979), com Alan Musgrave, que contém as ideias e opiniões sobre as estruturas das revoluções científicas de prestigiados epistemólogos, a partir dos temas apresentados e discutidos no Colóquio Internacional sobre Filosofia da Ciência, realizado em Londres, no ano de 1965. Enfim, Lakatos é considerado um filósofo da matemática e das ciências e tem normalmente seu nome relacionado aos chamados "Programas de Pesquisas Cientificas", expressão que utilizava para descrever como se dá o avanço das ciências.

\section{Epistemologia racionalista-crítico dos programas de pesquisa}

A epistemologia de Lakatos teve influências tanto do idealismo de Hegel e de Marx, quanto da teoria do conhecimento do filósofo britânico, o amigo Karl Popper, constituindose em uma das mais importantes reflexões na área da Filosofia da Ciência no século XX (MOREIRA; MASSONI, 2011). Lakatos adaptou e ampliou as ideias da Filosofia da Ciência de Popper (2007) e Thomas Kuhn (2006) para a Filosofia da Matemática.

Nessa perspectiva, defendeu a ideia de que o conhecimento acontece essencialmente no mundo das ideias e no mundo do conhecimento articulado. Sua teoria, exposta na obra Metodologia dos Programas de Pesquisa Científica (1989), buscou apresentar uma explicação lógica para o pensar e o fazer científico, identificando as "revoluções científicas" como progressões racionais. Nessa obra, considerou a Ciência 
um imenso "Programa de Pesquisa", e ponderou a "suprema heurística de Popper: arquitetar conjeturas que tenham maior conteúdo empírico do que as predecessoras" (LAKATOS, 1989, p.162).

Sustentou, em sua teoria, que um "Programa de Pesquisa" possui um "núcleo firme", composto pela teoria ou conjunto de hipóteses lançadas como verdadeiras e, por isso, convencionalmente aceitas, irrefutável, mesmo que provisoriamente. $E$, no desenvolvimento do "Programa", designou a existência de uma "heurística" negativa e outra positiva. A primeira seria a regra metodológica que indica os caminhos de investigação que devem ser evitados, induzindo o cientista a fazer modificações nas hipóteses auxiliares e não no núcleo, e a segunda indica os caminhos que devem ser seguidos, orientando a organização conceitual metodológica e empírica do "Programa de Pesquisa" (COVA; INCIARTE; PRIETO, 2005; BORGES, 2008).

Por conseguinte, Lakatos (1989) argumentou que um "Programa de Pesquisa" também conta com um "cinturão protetor" constituído de teorias e hipóteses auxiliares protegendo o "núcleo firme", e este sim sofre as alterações e expansões orientadas pela "heurística" positiva. Assim, o desenvolvimento do "Programa de Pesquisa" é composto por uma sucessão de modelos crescentes em complexidade, podendo ser "progressivo" ou "regressivo".

Um "Programa de Pesquisa" é teoricamente "progressivo" quando cada modificação no "cinturão protetor" conduz a novas e inesperadas explicações de um fato já conhecido (retrodições) ou "antecipações" daquilo ainda não observado (predições), e empiricamente "progressivo" no caso de pelo menos uma das predições ser comprovada (SILVEIRA, 1996, p. 223). O "Programa de Pesquisa" regride ou degenera quando seu crescimento teórico não acompanha o crescimento empírico.

Lakatos (1989), contrariando Kuhn (2006), que considerava a "revolução científica" irracional e uma questão da psicologia das multidões, defendia que a "revolução científica" é um processo racional de superação de um "Programa de Pesquisa" por outro. Entretanto, adepto das ideias de Popper, de que os "Programas de Pesquisa" se modificam de forma linear, sua teoria enfatiza a ocorrência histórica e a necessidade de pluralismo teórico, na certeza de que o progresso do conhecimento depende da existência de "Programas de Pesquisa" concorrentes e que a superação de um "Programa" por outro ocorre de forma temporalmente extensa.

Afastando-se da ideia de uma proposta metodológica universal e posicionando-se a favor de uma metodologia local, por convenções, Lakatos se aproxima do "anarquismo" epistemológico de Feyerabend (2011). Contudo, as duas teorias se diferenciam pelo fato de que Lakatos considera ser possível avaliar a posteiori o desempenho de um "Programa de Pesquisa", dada sua racionalidade ou irracionalidade, enquanto Feyerabend considera e valoriza a incomensurabilidade de uma teoria em relação a outra.

$\mathrm{Na}$ metodologia de Lakatos (1989) é desejável a existência de teorias em competição, considerando que a história da ciência não é a história de teorias sucessivas, conforme pensava Kuhn (2006), mas de teorias concorrentes. O cientista não abandona uma teoria a partir do seu falseamento, mas faz o possível para mantê-la, atribuindo valores às ideias que a falseou para identificá-las como comprovações da própria teoria. 
Nesse sentido, o conhecimento cresce seja qual for a noção de verdade e de realidade que assumimos, considerando que a importância de que haja crescimento sobressai a importância de que haja conhecimento e, por isso, é preciso que se tenha uma metodologia racional para o processo do desenvolvimento do conhecimento científico (BORGES, 2008).

A "ciência", segundo Lakatos (1989), não avança através de "conjecturas" isoladas, mas por meio de "Programas de Pesquisa". Ou seja, defende como lógica de pesquisa científica o falsificacionismo metodológico de base evolutiva. Nesse processo, sobrevivem as teorias mais aptas, que apresentam excesso de conteúdo corroborado em relação às teorias anteriores e que antecipam fatos novos, considerando a existência de uma demarcação entre teorias científicas e não científicas. A reiterada substituição de "Programas de Pesquisa Regressivos" por "Programas de Pesquisa Progressivos" caracteriza o avanço do conhecimento científico.

\section{A perspectiva histórico-filosófica da matemática}

Na perspectiva de Lakatos (1978), a Filosofia da Matemática deve levar em consideração as questões externas, como o contexto social e histórico, e as questões internas, inerentes ao conhecimento, existência e justificação. Para o autor, a visão falibilista considera o conhecimento matemático falível e passível de correções, e que essa proposta reconhece que os erros nos levam a reconsiderar que a teoria está, desta forma, em constante crescimento.

Lakatos ofereceu uma postura metodológica, propondo um conjunto de normas para guiar o desenvolvimento e o progresso do campo matemático, numa visão histórica e pedagógica, demonstrando sua preocupação de como ensinar corretamente Matemática (BARBOSA; MENEGHETTI, 2010).

Sobre Filosofia da Matemática, sua teoria levou em consideração a atividade dos matemáticos priorizando a prática. $\mathrm{Na}$ obra Provas e refutações: a lógica do descobrimento matemático (1978), postumamente publicada, apresenta sua epistemologia da Matemática, o método de "Provas e Refutações", como uma reconstrução racional da História da Matemática.

O texto é apresentado na forma de um diálogo socrático que considera a figura fictícia de um professor, com uma turma de alunos, a discutir conjecturas e contraexemplos sobre a fórmula de Euler. Trata-se da interpretação histórica da relação de Euler $(\mathrm{V}-\mathrm{A}+\mathrm{F}=2)$, onde o número de vértices, $\mathrm{V}$, diminuído do número de arestas, $A$, e somado ao número de faces, $F$, de um poliedro regular é igual a 2. Apresenta-se contraexemplos surgidos ao longo da história e que contribuíram para que as hipóteses fossem "lapidadas" (LAKATOS, 1978).

Em matemática, quando se trata de uma conjectura, em geral, basta encontrar um contraexemplo para descartá-la. Porém, quando se trata de uma prova, e é apresentado ou encontrado, um contraexemplo, parece que seria precipitado abandonar a teoria toda. Nesse sentido, dividir a prova em lemas e verificar se esse contraexemplo não está desmentindo um desses lemas, ajuda a não abandonar a prova, mas sim a melhorá-la. 
Na obra Provas e refutações: a lógica do descobrimento matemático (1978), Lakatos mostra um padrão de descobertas matemáticas, que consiste nas seguintes fases: a) Apresentação de uma conjectura primitiva; b) Prova (experimento mental que decompõe a conjectura primitiva em subconjecturas ou lemas); c) Surgimento de contraexemplos "globais" à conjectura primitiva; d) Reexame da prova: localiza-se o "lema condenado" para o qual o contraexemplo global é um contra-exemplo "local", podendo esse ter permanecido anteriormente "oculto" ou pode ter sido mal identificado; d) São examinados provas e outros teoremas para verificar se o lema recentemente achado ou o novo conceito gerado pela prova ocorre neles; f) As consequências até então aceitas da conjectura original e agora refutadas são conferidas; g) Os contraexemplos convertem-se em novos exemplos - abrem-se novos campos de investigação.

Nessa situação fictícia, apresentada na obra, os alunos são levados a assumir uma atitude ativa e participativa nas discussões e no desenvolvimento das ideias matemáticas, maneira pela qual o Lakatos tentou mostrar que a Filosofia da Matemática não pode ignorar a história da Matemática, levando-nos a perceber que o conhecimento não é estático, mas está se constituindo ao longo dos séculos.

Entretanto, ainda predomina no ensino de ciências uma concepção empiristaindutivista, como por exemplo, nos livros didáticos e roteiros de laboratório utilizados para o ensino. Pode-se observar, nessa concepção de ensino, que a observação é a fonte do conhecimento, e se constitui em uma síntese do que foi observado, com as teorias científicas descobertas de dados empíricos e ainda o verdadeiro conhecimento como livre de pressupostos, sendo que a imaginação e a criatividade não devem interferir no processo de obtenção de conhecimento.

Essas características do ensino, impedem o aluno de ser ativo e questionador, pois toma o conhecimento como algo pronto e acabado. Por isso, destaca-se que alguns princípios da epistemologia racionalista crítica de Lakatos podem ser usados no ensino de ciências, no sentido de melhorá-lo. Desses princípios, sublinha-se o fato de toda observação e experimentação estarem tomadas de teorias e pressupostos que o indivíduo carrega consigo. Logo, os conhecimentos prévios determinam como vemos a realidade, não podendo, nesse sentido, existir uma observação neutra; e, ainda, que o conhecimento científico é uma construção humana que intenciona descrever, compreender e agir sobre a realidade, sendo, portanto, provisório e sujeito a alterações.

Nesse contexto, segundo Beltrán (1996), Lakatos nos indica que a compreensão da prova de uma teoria precisa passar pela reconstrução racional da história da prova, ou seja, as mudanças conceituais geradas pelas novas provas resultam em novo marco teórico que se incorpora naqueles já existentes e precisam ser entendidas por alunos e professores.

$\mathrm{Na}$ estrutura metodológica, proposta por Lakatos, a aceitação de uma conjuntura se dá pelo resultado do desenvolvimento de um processo, por meio de provas, buscando reforçar sua afirmação ou, se suspeitar não ser verdadeira, derivar sua negação por meio de um ou mais contraexemplo. O desenvolvimento matemático não se dá somente pelo número crescente de teoremas, mas sim pelo refinamento daqueles já existentes. Nessa perspectiva, Beltrán (1996), ressalta que nenhum resultado é definitivo, isto é, toda prova de um teorema, obtida pelo método de provas e refutações é cabível de revisão a 
qualquer momento e, com isso, os resultados dos estudos matemáticos serão sempre temporários e sujeitos a historicidade. Na sua concepção, os teoremas da matemática informal são falsificadores em potencial para a teoria matemática formal.

Portanto, Lakatos (1978) nos oferece uma concepção racionalista do ensino de Matemática, que por sua vez se opõe à concepção empirista-indutivista. Ou seja, a teoria lakatosiana se apresenta contrária àquela em que a prática pedagógica do professor expõe os teoremas e axiomas, apresenta alguns exemplos e lista atividades em que os alunos aplicam o que foi exposto. Nessa lógica, os textos matemáticos seriam mais simples de se entender se atribuíssem os valores históricos inerentes, refletindo o desenvolvimento do conhecimento para chegar a uma prova. Sob esta ótica, o processo pedagógico possibilitaria melhor aprendizado dos teoremas, pois não seria uma análise estática de definições, mas um acompanhamento do processo de desenvolvimento e surgimento do conhecimento. Enfim, essa proposta metodológica tem muito a contribuir com a formação e a prática docente, sobretudo, no ensino e na pesquisa dos teoremas que embasam o conhecimento matemático, seja na "Álgebra", na "Geometria" ou no "Cálculo", pensando na formação para a atuação no ensino de Matemática.

\section{O ensino e aprendizagem da matemática}

A concepção epistemológica de Lakatos (1978), para o ensino, é racionalista, contrária à concepção empirista-indutivista, presente em inúmeras situações de ensino da Matemática. Para os empiristas-indutivistas, desde Bacon (KÖHNLEIN; PEDUZZI, 2002), o caminho para a investigação e a descoberta da verdade é o da indução. Considera-se que, partindo dos dados particulares e dos sentidos é possível abstrair os axiomas, ascendendo de forma reta e ordenada, para chegar aos princípios de generalidade. Aqui, o cientista cognitiva e emocionalmente não se envolve com o objeto a ser estudado. $A$ natureza se manifesta e oferece os fatos e cabe ao cientista descobri-los. As etapas que levam ao conhecimento científico são: observação de um grande número de fatos e experimentos, elaboração de hipóteses, comprovação por meio de experimento (s), conclusões, leis e teorias gerais.

$\mathrm{Na}$ atualidade, várias são as diretrizes e orientações nacionais, bem como as diversas teorias tem reconhecido e exposto as limitações e suas preocupações sobre essa visão. Enquanto as correntes filosóficas da matemática dominantes, no final do século XIX e início do XX, reduziam o conhecimento matemático a um único aspecto, lógico, intuitivo ou formal, atualmente se busca perceber e estudar a Matemática como parte da criação humana, sujeita a erros e correções (MENEGHETTI, 2009).

Para Lakatos, a Matemática é uma ciência quase-empírica, no sentido de que a prática na Matemática passou a ser valorizada, representando uma nova direção na Filosofia da Matemática, sobretudo, no século XX. Essas ideias embasam as Diretrizes Curriculares (BRASIL, 1996) e os Parâmetros Curriculares Nacionais (BRASIL,1999) que orientam as práticas educativas, sejam no ensino básico ou superior.

$\mathrm{Na}$ história da educação brasileira identificam-se alertas para a necessidade de uma formação geral do aluno, que leve em consideração a visão histórica do conhecimento, na construção da aprendizagem, numa perspectiva de fornecer ao aluno 
uma visão crítica de mundo. Porém, o que ainda está presente, na maioria das práticas escolares, é uma concepção empirista-indutivista.

Para o empirismo, o conhecimento se origina a partir da observação e para o indutivismo a construção do conhecimento ocorre do particular ao geral, ou seja, parte-se dos fatos às teorias. Nessa proposta epistemológica, costuma-se trabalhar com roteiros de laboratórios, logo a concepção empirista-indutiva de ensino acontece e faz com que as aulas se desenvolvam por meio de orientações prévias do professor (monitor), sabedor do que será encontrado, que por sua vez apenas acompanha as atividades dos alunos.

O físico norte-americano, Richard Feynman, segundo Bassanezi (2002), descreveu sua perplexidade diante do rumo que estava tomando o sistema educacional brasileiro, quando de sua visita ao Brasil, na década de 50. Ele assistiu a uma aula sobre momentos de inércia a uma turma de alunos e, segundo o físico, somente ele estava entendendo do que o professor falava, pois em nenhum momento foram utilizados recursos que ajudassem os alunos a compreender o assunto, tal como a dificuldade de abrir uma porta empurrando-a quando tiver com peso na parte de fora comparada com a dificuldade de abri-la se esse mesmo peso estivesse perto dos gonzos. Para o físico, os estudantes decoravam as afirmações da aula sem compreender o assunto.

A visita aconteceu na década de 50 e o fato descrito ainda pode ser percebido em realidades atuais, tanto na Educação Básica quanto na Ensino Superior. Ao manter um ensino basicamente tradicional, desvinculado da realidade do aluno, acaba-se por não atender às necessidades destes e, consequentemente, da própria sociedade. Assim, há uma forte tendência da escola perder o sentido de sua existência.

$\mathrm{Na}$ sequência, passamos a apresentar algumas pesquisas realizadas sobre as chamadas "Concepções Alternativas" (CAs) dos estudantes, isto é, concepções de conhecimentos que os alunos possuem com significados contextualmente errôneos, não compartilhados pela comunidade científica, mas que são importantes ferramentas de explicação para o fenômeno do porquê determinados alunos não apreendem a ciência que lhe é ensinada. Conforme Silveira, "a existência das CAs mostra que os alunos são construtores de idéias que objetivam dar conta do mundo, da realidade" (1996, p. 10).

Frequentemente, porém, os estudantes resistem em abandonar as teorias nas quais acreditam, passando pelo ensino escolar sem as modificar. Disso decorre a importância de, no ensino de ciências e matemática, compreender e levar em consideração essas concepções previamente construídas.

Com o objetivo de melhor ensinar e formar os alunos com determinada racionalidade, o trabalho de Silva, Nardi e Laburu (2008) apresenta a "Reconstrução Racional Didática" (RRD) como um passo importante para uma estratégia de ensino inspirada em Lakatos e melhorando algumas propostas existentes na literatura. A RRD propõe uma aproximação teórico-prática entre a metodologia dos "Programas de Pesquisa Científica" e uma metodologia das "Concepções Alternativas" dos alunos perante os conhecimentos científicos, apresentando uma sequência objetiva de passos: a) revelação das concepções alternativas dos alunos em determinado conteúdo, através de questionários, questões orais ou discussões em grupo, para que essas CAs possam ser usadas como se fossem os "Programas de Pesquisa Científica"; b) apresentação de 
duas teorias científicas rivais, de modo a incluir a que se pretende ensinar, discutindo fenômenos que ambas as teorias expliquem; c) avaliação acerca da compreensão que se obteve ao apresentar as teorias que competem; d) apresentação da RRD para os alunos, seguida de discussão e busca de superação de uma teoria frente à outra direcionada pelos critérios do falsificacionismo (seu desenvolvimento permite alcançar uma interpretação dos fatos contraditórios à teoria antecessora); e) discussão racional entre as CAs dos estudantes, resgatadas do passo inicial, e a teoria científica que foi vencedora na etapa anterior, com confrontos entre as explicações e previsões que as CAS e a teoria científica fazem sobre os fenômenos e clareando as interpretações; f) insatisfação com o "Programa Alternativo", aqui o professor tem um papel essencial ao enfraquecer o núcleo do deste "Programa" seguindo a analogia com os critérios de eliminação de teorias. Assim terá maior força heurística o "Programa de Pesquisa Científica", que por sua vez terá uma melhor aceitação por parte dos estudantes; g) por fim, o passo será a verificação da assimilação da nova teoria.

Porém, conforme Silva, Nardi e Laburu "é necessário afirmar que o processo de ensino assim estruturado a partir de detalhes específicos da epistemologia de Lakatos limita-se a uma analogia que precisa ser mais bem discutida" (2008, p. 14). Por isso, ressalta-se a importância dos professores conhecerem e discutirem propostas de ensino elaboradas a partir da epistemologia lakatosiana.

Na mesma direção, encontra-se o trabalho de Laburu, Arruda e Nardi (1998), que objetiva analisar a dinâmica do conhecimento construído em sala de aula através do que eles chamam de "Programas": "Programa Alternativo" (PA), "Programa Transitório" (PTr) e "Programa Científico" (PC). O contexto analisado são as aulas da disciplina de Física, do segundo ano do Nível Médio, com 32 alunos, em que se trabalhou especificamente com os conceitos de temperatura e calor.

No decorrer do texto, os autores apresentam transcritas algumas falas de alunos que claramente podem ser classificadas dentro dos chamados "Programas" que eles instituíram.

No intervalo da aula observada, podemos basicamente caracterizar três idéias distintas dos alunos que estiveram tomando parte nas discussões: uma baseada nas concepções alternativas, uma outra que procura defender posições científicas ensinadas e, ainda, por último, uma que mescla estas últimas (LABURU; ARRUDA; NARDI, 1998, p.30).

$\mathrm{Na}$ experiência realizada, tem-se presente as "Concepções Alternativas" e as dificuldades encontradas para convencer os alunos das vantagens da teoria científica. Nesse sentido, mais uma vez ressalta-se a importância de que o professor leve em consideração essas construções feitas pelos estudantes no processo de ensino.

No campo da Matemática, destaca-se o trabalho de Silva e Moura (2015), que investiga as similaridades entre a filosofia de Lakatos (1978) e o trabalho com investigações matemáticas. Nesse sentido, a obra Provas e refutações: a lógica do descobrimento matemático (1978), apresenta uma considerável abrangência junto à comunidade de educadores matemáticos, tendo como um dos principais motivos o fato de considerar a matemática como uma ciência falível (SILVA; MOURA, 2015, p.280). 
Destaca-se no processo de trabalho com ensino e pesquisa na Matemática, a visão de que essa área do conhecimento, enquanto atividade humana, é passível de falhas, a procura por regularidades, o diálogo e debate constantes e a valorização das ideias dos estudantes. Esses são alguns pontos de convergência que podem ser destacados entre a filosofia lakatosiana e o trabalho com investigações matemáticas em sala de aula. Porém, ressalta-se que existem alguns distanciamentos: Lakatos não tinha preocupação com o ensino de matemática, seu alvo era o processo de construção de novos conhecimentos matemáticos, além disso, o processo de refutação, em na obra, é iniciado junto com a prova; já no trabalho com investigações, a prova geralmente é o último passo a ser alcançado. A partir dessas aproximações e distanciamentos, cabe ao professor ou pesquisador avaliar e refletir sobre essas possibilidades que se abrem ao conhecer as obras de Lakatos.

O grande desafio hoje é transcrever o currículo do "paradigma do exercício" para "cenários de investigação". Para Bassanezi (2002), essa concepção de professor descreve o paradigma do exercício como aquele em que o professor explica o conteúdo, apresenta alguns exemplos da sistematização para resolvê-los e propõe uma lista de exercícios para que o aluno repita o processo mostrado, constituindo-se, assim, uma "zona confortável" para o educador. Os cenários para investigação representam uma "zona de risco", segundo classificam Barbosa e Meneghetti (2010), onde as atividades que surgem não estão programadas pelo professor. Os alunos pesquisam os dados e surgem discussões que comumente não aconteceriam em aulas de Matemática.

Dada à relevância da Matemática e sua aplicabilidade nas diversas atividades sociais e profissionais, destaca-se o pensamento de Almeida (2003), cuja ênfase recai na importância de se abrir espaço em sala de aula para atividades de investigação, não apenas porque permitem a abordagem dos conteúdos, mas, sobretudo, porque possibilitam a concretização dos objetivos do ensino da Matemática, que permeiam a busca de uma formação do aluno como cidadão, capaz de produzir conhecimento, ao invés de somente repetir.

Nesse sentido, faz-se necessário que se oportunize o desenvolvimento de valores e atitudes fundamentais para que o aluno aprenda a aprender, como alerta o texto constante nos Parâmetros Curriculares Nacionais (BRASIL, 1999). Essas características devem ser demonstradas pelo aluno, para que o ensino de Matemática assuma suas responsabilidades frente à necessária formação.

Na perspectiva do racionalismo crítico de Lakatos (1989), o aluno precisa ser ativo, como um construtor de ideias. E, considerando a atividade matemática como atividade do homem, as orientações, diretrizes e teorias, de maneira geral, têm caminhado na mesma direção, por uma formação integral da pessoa para que conheça o mundo e saiba como lidar com as mais diversas situações em defesa de sua realização pessoal e de sua sociedade. Enfim, segundo os Parâmetros Curriculares (BRASIL, 1999), vivemos em um mundo em constante mudança e é preciso ofertar o desenvolvimento e a promoção dos alunos para a vida no trabalho e em sociedade.

A matemática desempenha importantes papéis nessa formação: papel formativo, porque a Matemática pode contribuir para estruturar o pensamento e o raciocínio dedutivo; e papel instrumental, já que é uma ferramenta para a vida e para as tarefas nas 
atividades humanas, e precisa ser importante instrumento para as outras áreas e para a atividade profissional.

Nesse sentido, faz-se necessário que se oferte situações de ensino em que o aluno reconheça a importância e aplique os conhecimentos matemáticos, desde suas ações na escola até fora dela. Sugere-se, com isso, que as práticas educativas se voltem para as questões práticas e, sempre que possível, para a aplicabilidade e valorização da historicidade do conhecimento científico.

A Matemática se constitui, na atualidade, como um instrumento que ajuda a modelar situações com referência à realidade e interpretá-las. O processo de ensino e aprendizagem que valoriza as questões históricas e práticas pode dar condições de formação, ao aluno, para agir sobre esta de forma crítica e reflexiva. Contudo, a Matemática não pode ser concebida somente como instrumental ou formativa, mas também como Ciência, com suas "definições, demonstrações e encadeamentos conceituais e lógicos” (BRASIL, 1999, p. 40), e o aluno precisa percebê-los como meios para construir novos conceitos e novas estruturas, validando intuições e dando sentido a técnicas que são aplicadas.

Nessa perspectiva, almeja-se uma postura de aluno que reconheça o conhecimento matemático como algo em constante desenvolvimento, e que este está imerso num meio tecnológico que leva a renovações constantes dos saberes e, ainda, que o desenvolvimento não acontece somente de forma solitária, mas também nas relações com as outras pessoas e com o mundo.

Silveira (1996), fundamentado na epistemologia racionalista crítica de Lakatos, destaca seis princípios para o ensino de ciências, que se reconhecem intimamente relacionados ao que se espera do ensino da Matemática: a) observação e experimentação, sozinhas, não produzem conhecimento; b) toda observação ou experimentação apresenta-se impregnada de teorias e pressupostos; c) conhecimento prévio determina como vemos a realidade e influencia a observação; d) conhecimento científico é visto como uma construção humana que serve para descrever, compreender e agir sobre a realidade; e) obtenção de um novo conhecimento, como ato que envolve imaginação, intuição e razão, está sujeito a diferentes influências; e) aquisição de novos conhecimentos é difícil e problemática e se dá a partir de conhecimentos anteriores.

Por conseguinte, entende-se o aluno como ser ativo, que constrói suas ideias e seu conhecimento, justamente o que os Parâmetros Curriculares Nacionais (1999) idealizam. Para isso, cabe aos professores pensar e aplicar ações que conduzam a um ensino da Matemática que envolva questões históricas e atuais do mundo que nos cerca, que leve os alunos à descoberta, ao estudo, à dedicação. Ações que nos levem a desfrutar ao máximo dos recursos tecnológicos disponíveis, que aí estão a nosso - professores, alunos e sociedade em geral - favor. E, acima de tudo, que se promova um ambiente para uma aprendizagem com significado ao estudante e significante para a sociedade em que ele vive (MOREIRA, 1999).

O que precisa ser consideravelmente reavaliado no fazer pedagógico é a figura do professor como detentor do saber e do aluno como receptor. Infelizmente, segundo Demo, o que "predomina entre nós a atitude do imitador, que copia, reproduz e faz prova. 
Deveria impor-se a atitude de aprender pela elaboração própria, substituindo a curiosidade de escutar pela de produzir" (1990, p. 10).

Contrariando essa postura, o que se espera é incorporar, no fazer didático, a busca pela concretização de novos rumos, como pesquisar a própria prática, criar situações de estudo e pesquisa no ambiente escolar, proporcionar a contextualização e a interdisciplinaridade valorizando a intuição, a imaginação e a razão. Logo, espera-se oportunizar a construção do conhecimento científico e a percepção de que este é uma construção humana que serve para descrever, compreender e agir sobre a realidade.

Segundo Japiassu (1976), o tema da interdisciplinaridade é uma questão que inquieta e desafia, pela sua complexidade, os atuais e futuros educadores. Em um sistema de ensino ainda tão engessado na disciplina, romper com os limites disciplinares é difícil, mas não impossível. Trata-se de discutir os pressupostos e sentidos da interdisciplinaridade, a importância de sua inserção na construção do conhecimento em sala de aula e suas implicações na prática docente. Isso por que entendemos que a Interdisciplinaridade, no âmbito da educação matemática, amplia a interação entre professores e alunos sem perder a especificidade do assunto tratado. Ou seja, ela não anula as disciplinas, mas pede que as mesmas dialoguem entre si numa perspectiva educacional em busca de inovação.

Mais ainda, em mundo globalizado que apresenta muitos desafios ao homem, fazse necessário romper com modelos tradicionais de ensino. Considerando a rapidez com que ocorrem as mudanças na área do conhecimento e da produção, exigindo uma atualização contínua e colocando novas exigências para a formação do educando, é que a interdisciplinaridade se insere na ousadia de novas abordagens de ensino, na educação básica e, especialmente, nos cursos de formação de professores.

Percebe-se cada vez mais, que o caráter disciplinar do ensino formal dificulta a aprendizagem do aluno, não estimula ao desenvolvimento da inteligência, à resolução de problemas e estabelecimento de conexões entre os fatos, conceitos, isto é, ao pensar sobre o que está sendo estudado. Porém, em uma proposta de ensino interdisciplinar, é necessário determinar o valor de cada disciplina, aqui de modo particular a filosofia e a história, seu nível teórico, suas estruturas e a intencionalidade de seu papel no currículo escolar ou acadêmico. Esses fundamentos possibilitam entender que a interdisciplinaridade é muito mais que uma simples integração de conteúdo. Para que ocorra a interdisciplinaridade não se trata de eliminar as disciplinas, mas de torná-las comunicativas entre si, concebê-las como processos históricos e culturais, necessárias à atualização das práticas e do processo de ensino-aprendizagem.

A proposta da interdisciplinaridade visa estabelecer ligações de complementaridade, convergência, interconexões e passagens entre os conhecimentos. As atividades pedagógicas precisam contemplar conteúdos e estratégias de aprendizagem que capacitem o estudante para a vida em sociedade, a atividade produtiva e experiências subjetivas, visando à integração.

Contudo, percebe-se o conceito de interdisciplinaridade como polissêmico, isso significa que a atitude interdisciplinar depende da história vivida, das concepções apropriadas e das possibilidades de olhar por diferentes perspectivas uma mesma 
questão. A preocupação interdisciplinar não é um fenômeno recente. Porém, na atualidade, na área de ensino de ciências e matemática, torna-se necessário repensarmos a produção dos saberes na prática e na teoria, levando-se em conta as suas implicações mútuas, seus valores, seus fins e motivações para a vida humana. É importante enfatizar que a interdisciplinaridade supõe um eixo integrador com as disciplinas de um currículo, para que os alunos aprendam a olhar o mesmo objeto sob perspectivas diferentes.

Assim encarar uma mudança na educação, como a interdisciplinaridade, implica uma atitude permanente de crítica e reflexão, de compromisso e responsabilidade com a tarefa de educar. A postura que os educadores devem adotar diante das mudanças na educação deve ser: pensar, refletir, criticar e valorar o que está acontecendo nos âmbitos escolares presentes e futuros. Essa postura é a maior dificuldade a ser enfrentada, pois ela é exigente e demanda dos envolvidos no processo tempo e conhecimento, capacidade de trabalhar colaborativamente e de adotar metodologias de trabalho diferenciadas. Portanto, a interdisciplinaridade impõe aos educadores a exigência de um aperfeiçoamento, em busca da melhora da educação, o que exige uma reflexão profunda por parte de todos aqueles que terão de uma forma ou de outra a responsabilidade específica na formação de novas gerações.

O ensino interdisciplinar e contextualização de saberes pode influenciar diretamente na produção de significados dos conhecimentos matemáticos pelo aluno, ao possibilitar a relação teoria e prática. O ensino da Matemática que viabiliza a contextualização pode retirar o aluno da passividade no processo educativo e levá-lo a descobrir a importância da sua formação para sua vida e para o mundo. Por meio da relação teoria e prática, os alunos podem construir suas competências para lidar com situações escolares ou extraescolares. A saber, a contextualização dos conteúdos de ensino pode provocar aprendizagens significantes e mobilizar o aluno a estabelecer relações de reciprocidade entre ele e o conhecimento em construção.

Moreira (1999) faz uma distinção entre a aprendizagem significante e a aprendizagem significativa. Aprendizagem significante é compreendida como aquela geradora de significados na vida cotidiana do aluno e da sociedade. Trata-se de uma aprendizagem que, em algum momento, seja na escola ou fora dela, a pessoa reconheça a importância e a necessidade do que aprendeu enquanto aluno. A aprendizagem significante é mais do que uma acumulação de fatos, pois é aquela que provoca modificação no comportamento do indivíduo, ou na orientação da ação futura, ou nas suas atitudes e na própria personalidade. Trata-se de uma aprendizagem penetrante que não se limita a um aumento de conhecimentos.

Por seu turno, a aprendizagem significativa focaliza muito mais o aspecto cognitivo da aprendizagem e a expressão significativa vem da ideia de cognição que emerge na interação entre nova informação e o conceito subsunçor especificamente relevante. Portanto, a noção de aprendizagem vai muito além do cognitivo, e a expressão significante está muito mais relacionada à significação pessoal - significado para a pessoa.

Nesta perspectiva, torna-se vital que pensemos no aluno como pessoa. A atividade matemática enquanto atividade humana, está sujeita a mudanças históricas e sociais, e 
estas por sua vez estão intimamente relacionadas às questões educacionais. Por isso, faz-se necessário tratá-la na forma interdisciplinar e também na forma disciplinar. $\mathrm{Na}$ prática educativa é preciso priorizar o estudo e a aplicabilidade dos conhecimentos científicos, mas valorizando suas especificidades disciplinares. É preciso destacar e valorizar o caráter disciplinar do conhecimento que, a partir do seu aprofundamento será possível instrumentar-se para aplicações gerais e estabelecer as relações entre as diferentes áreas. Trata-se de reconhecer a importância do desenvolvimento do conhecimento científico específico para que se consiga fazer a aplicabilidade e a relação com as outras áreas.

\section{Considerações finais}

Na teoria epistemológica de Lakatos (1989), o avanço do conhecimento científico consiste na permanente substituição de Programas de Pesquisa Científica regressivos por "Programas de Pesquisa" progressivos e, de forma subjacente, na constante substituição de hipóteses. O avanço se dá por meio de Programas concorrentes.

$\mathrm{Na}$ Filosofia da Matemática, segundo Lakatos, trata-se de considerar as questões externas, como o contexto social e histórico, e as questões internas, inerentes ao conhecimento, percebendo a visão falibilista do conhecimento matemático, passível de correções, reconhecendo que os erros nos levam a reconsiderar que a teoria que está em constante crescimento.

Lakatos ofereceu uma diretriz metodológica que serve guia para o desenvolvimento e o progresso do campo do conhecimento matemático, numa visão histórica e pedagógica, enfatizando uma preocupação com o processo de ensino e aprendizagem da ciência matemática. Neste contexto, identificamos aspectos de sua teoria nos ideais que se apresentam para o ensino e aprendizagem da Matemática na atualidade, para enfrentar as dificuldades que os alunos têm demonstrado na compreensão dos conhecimentos dessa área, seja no ensino básico ou superior.

As diretrizes, orientações curriculares e teorias educacionais contemporâneas apontam para a necessidade de uma postura educativa que valorize o aluno como ser ativo, permeando práticas que contemplem a investigação, o questionamento, o uso da intuição e dos conhecimentos prévios, sempre valorizando os aspectos históricos e sociais intimamente relacionados ao saber matemático.

Identifica-se a necessidade de uma prática educativa que ofereça ao aluno situações que favoreçam a contextualização, a aplicabilidade dos conhecimentos escolares, a interdisciplinaridade, oportunizando entrelaçar os saberes das diferentes áreas e com o mundo em que vive, e a disciplinaridade, valorizando o conhecimento específico como instrumento para estabelecer e compreender suas relações entre as diferentes áreas.

Neste contexto, o aluno precisa ser ativo e construtor de suas ideias e de seu conhecimento, precisa reconhecer o desenvolvimento histórico do conhecimento científico e sua importância para seu próprio crescimento pessoal e da sociedade em que vive.

Lakatos considerou que as teorias matemáticas seriam mais simples de se entender se atribuíssem os valores históricos inerentes, refletindo o desenvolvimento do 
conhecimento para chegar a uma prova. O processo pedagógico possibilitaria melhor aprendizado dos teoremas, sem ser estático, mas na forma de estudo e acompanhamento do processo de desenvolvimento do conhecimento.

Ao longo do texto, foram apresentados três trabalhos que trazem uma analogia da metodologia dos Programas de Pesquisa com o ensino de ciências e também um trabalho que traz especificamente uma aproximação das discussões do método de provas e refutações na matemática com as atividades investigativas no ensino dessa ciência.

Com isso, percebe-se o quanto é possível fazer as aproximações de forma que venha a contribuir para um ensino cada vez mais voltado para o aluno e levando em consideração seus conhecimentos prévios. É claro que a transposição para a sala de aula não pode se dar de forma integral. Mesmo assim, é importante que os professores se apropriem dessa teoria, para que possam inclusive promover estudos e reflexões que indiquem se essas aproximações são ou não viáveis.

Portanto, o presente artigo encarregou-se de apresentar a importância da teoria histórico-epistemológica de Lakatos para se pensar a formação e a prática docente, o estudo e ensino dos teoremas que embasam o conhecimento matemático para a conquista de uma aprendizagem significante, que contribua para uma vida plena e feliz do ser humano e para o desenvolvimento da sociedade.

\section{REFERÊNCIAS}

ALMEIDA, L.M.W.; BRITO, D.S. Modelagem Matemática na sala de aula: algumas implicações para o ensino e aprendizagem da Matemática. CONFERÊNCIA INTERAMERICANA DE EDUCAÇÃo MATEMÁTICA, 11, Blumenau: FURB, 2003.

BARBOSA, G.; MENEGHETTI, R.C.G. Filosofia da Matemática do quase-emprirismo e História da Matemática: traçando algumas considerações sobre o ensino de graduação em Matemática. X ENEM. Salvador, 2010.

BYNUM. W. Uma breve história da ciência. Porto Alegre: L\&PM, 2013.

BASSANEZI, R.C. Ensino-aprendizagem com Modelagem Matemática: uma nova estratégia. São Paulo: Contexto, 2002.

BELTRÁN, P. La matemática de Lakatos: el papel de la prueba em la metodologia. La Ciencia de los Filósofos, Universidade de Sevilla, Espanha, p. 305-320, 1996.

BORGES. Imre lakatos e a metodologia dos programas de investigação científica. Curitiba: UFPR, 2008.

BRASIL. LEI 9394/96. Lei de Diretrizes e Bases da Educação Nacional. Brasília, 1996.

BRASIL. Parâmetros Curriculares Nacionais: Ensino Médio. Secretaria de Educação Média e Tecnológica. Ministério da Educação. Brasília, 1999.

COVA, A.; INCIARTE, A.; PRIETO, M. Lakatos y los programas de investigación científica. Una opción para la organización investigativa Nacional. Omnia, 11, 3, p. 83-108, 2005.

FEYERABEND, P. Contra o método. Lisboa: Relógio D' Água, 2011.

JAPIASSU, H. Interdisciplinaridade e patologia do saber. Imago: Rio de Janeiro, 1976. 
KÖHNLEIN, J.F.K.; PEDUZZI, L.O.Q. Sobre a concepção empirista-indutivista no ensino de ciências. Ciência Mão. USP, 2001.

KUHN, T.S. A estrutura das revoluções científicas. São Paulo: Perspectiva, 2006.

LABURU, C. E.; ARRUDA, S. M.; NARDI, R. Os programas de pesquisa de Lakatos: uma leitura para o entendimento da construção do conhecimento em sala de aula em situações de contradição e controvérsia. Revista Ciência \& Educação. Bauru, v. 5, n. 2, 1998.

LAKATOS, I. O falseamento e a Metodologia dos Programas de pesquisa Científica. In: LAKATOS, I.; MUSGRAVE, A. (org.). A crítica e o desenvolvimento do conhecimento. São Paulo: Cultrix, 1979.

LAKATOS, I. La metodología de los programas de investigación científica. Madrid: Alianza Editorial, 1989.

LAKATOS, I. A Lógica do Descobrimento Matemático: Provas e Refutações. Rio de Janeiro: Zahrar, 1978.

LAKATOS, I. Historia de la ciencia y sus reconstrucciones racionales. Madrid: Tecnos, 1987.

MENEGHETTI, R.C.G. O Intuitivo e o Lógico no Conhecimento Matemático: análise de uma proposta pedagógica em relação a abordagens filosóficas atuais e ao contexto educacional da matemática. Bolema. 22, 32, p. 161-188, 2009.

MOREIRA, M.A. Teorias de aprendizagem. São Paulo: EPU, 1999.

MOREIRA, M.A.; MASSONI, N.T. Epistemologias do século XX. São Paulo: EPU, 2011.

SILVA, G. H. G. da; MOURA, A. Q. O falibilismo de Lakatos e o trabalho com investigações matemáticas em sala de aula: possíveis aproximações. Acta Scientiae, Canoas, v.17, n.2, 2015.

SILVA, O. H. M. da; NARDI, R.; LABURU, C. E. Uma estratégia de ensino inspirada em Lakatos com instrução de racionalidade por uma reconstrução racional didática. Ensaio, Rio de Janeiro, v. 10, n.1, 2008.

SILVEIRA, F. L. da. A metodologia dos programas de pesquisa: a epistemologia de Imre Lakatos. Caderno Catarinense de Ensino de Física, v.13, n.3, 1996.

POPPER, K.R. A lógica da pesquisa científica. São Paulo: Cultrix, 2007.

Submissão: 13/02/2017

Aceite: 05/09/2017 